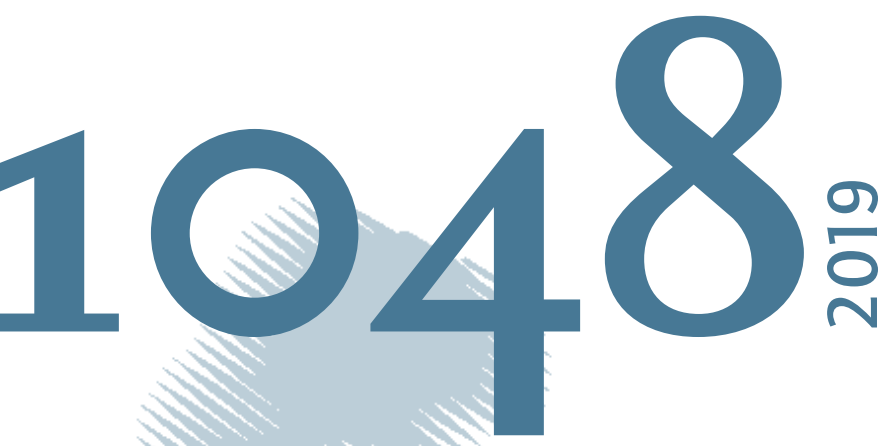

\title{
Being unengaged at work but still dedicating time and energy: A longitudinal study
}


This series presents research findings based either directly on data from the German SocioEconomic Panel (SOEP) or using SOEP data as part of an internationally comparable data set (e.g. CNEF, ECHP, LIS, LWS, CHER/PACO). SOEP is a truly multidisciplinary household panel study covering a wide range of social and behavioral sciences: economics, sociology, psychology, survey methodology, econometrics and applied statistics, educational science, political science, public health, behavioral genetics, demography, geography, and sport science.

The decision to publish a submission in SOEPpapers is made by a board of editors chosen by the DIW Berlin to represent the wide range of disciplines covered by SOEP. There is no external referee process and papers are either accepted or rejected without revision. Papers appear in this series as works in progress and may also appear elsewhere. They often represent preliminary studies and are circulated to encourage discussion. Citation of such a paper should account for its provisional character. A revised version may be requested from the author directly.

Any opinions expressed in this series are those of the author(s) and not those of DIW Berlin. Research disseminated by DIW Berlin may include views on public policy issues, but the institute itself takes no institutional policy positions.

The SOEPpapers are available at http://www.diw.de/soeppapers

\section{Editors:}

Jan Goebel (Spatial Economics)

Stefan Liebig (Sociology)

David Richter (Psychology)

Carsten Schröder (Public Economics)

Jürgen Schupp (Sociology)

Sabine Zinn (Statistics)

Conchita D'Ambrosio (Public Economics, DIW Research Fellow)

Denis Gerstorf (Psychology, DIW Research Fellow)

Katharina Wrohlich (Gender Studies)

Martin Kroh (Political Science, Survey Methodology)

Jörg-Peter Schräpler (Survey Methodology, DIW Research Fellow)

Thomas Siedler (Empirical Economics, DIW Research Fellow)

C. Katharina Spieß (Education and Family Economics)

Gert G. Wagner (Social Sciences)

ISSN: 1864-6689 (online)

German Socio-Economic Panel (SOEP)

DIW Berlin

Mohrenstrasse 58

10117 Berlin, Germany

Contact: soeppapers@diw.de

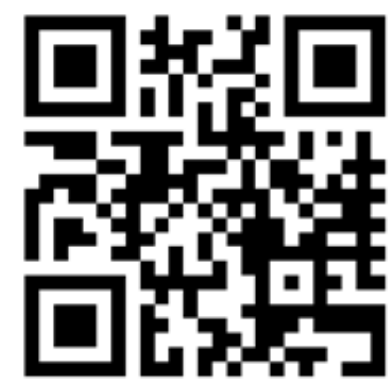




\title{
Being unengaged at work but still dedicating time and energy:
}

\section{A longitudinal study}

\author{
Sabine Hommelhoff \\ Friedrich-Alexander University Erlangen-Nürnberg \\ David Richter \\ German Institute for Economic Research, Berlin \\ Cornelia Niessen \\ Friedrich-Alexander University Erlangen-Nürnberg \\ Denis Gerstorf \\ Humboldt University Berlin \\ Jutta Heckhausen \\ University of California, Irvine
}

\section{IN PRESS (Motivation Science)}

C) 2019, American Psychological Association. This paper is not the copy of record and may not exactly replicate the final, authoritative version of the article. Please do not copy or cite without authors' permission. The final article will be available, upon publication, via its DOI:

\section{$10.1037 / \operatorname{mot} 0000155$}

\section{Author Note}

Sabine Hommelhoff and Cornelia Niessen, Institute of Psychology, Chair of Work and Organizational Psychology, Friedrich-Alexander University Erlangen-Nürnberg.

David Richter, German Institute for Economic Research, Berlin.

Denis Gerstorf, Department of Psychology, Chair of Developmental and Educational Psychology, Humboldt University Berlin.

Jutta Heckhausen, Department of Psychological Science, University of California, Irvine.

Correspondence concerning this article should be addressed to Sabine Hommelhoff, Institute of Psychology, Chair of Work and Organizational Psychology, Naegelsbachstr. 49c, 91052 Erlangen, Germany. Phone: +49 913185 64007, E-Mail: sabine.hommelhoff@ fau.de

Data are made publicly available by the German Institute for Economic Research (https://www.diw.de/en/soep). Our analyses scripts are available on OSF (https://osf.io/4mtvf/). 


\begin{abstract}
:
Overcommitted individuals cannot withdraw from work obligations. We examine whether work goal engagement attenuates the negative effects of overcommitment on work and health outcomes. For overcommitted professionals it should matter whether they dedicate time and energy to work goals they feel bound to or to goals they do not feel attached to (unengaged overcommitment). In a longitudinal study of 752 employees, we examined the interaction between overcommitment (T1) and work goal engagement (T2) in contributing to job and sleep satisfaction (T1 and T3). Results indicated that higher overcommitment and lower work goal engagement were associated with lower job and sleep satisfaction at T3, controlling for T1 job and sleep satisfaction. Overcommitment was only related to lower job satisfaction when work goal engagement was low. No interactive effect was found for sleep satisfaction. These findings support the essential role of goal engagement for well-being and adaptive development in the work domain.
\end{abstract}

Keywords: overcommitment, work goal engagement, job satisfaction, sleep satisfaction, wellbeing at work 
Being unengaged at work but still dedicating time and energy: A longitudinal study

Overcommitment, the inability to withdraw from work obligations (Joksimovic, Starke, Knesebeck, \& Siegrist, 2002; Siegrist, 1996), is a relatively stable stress component that is associated with exhaustion, job dissatisfaction, and poor sleep quality (de Jonge, Bosma, Peter, \& Siegrist, 2000; de Jonge, van der Linden, Schaufeli, Peter, \& Siegrist, 2008; Kudielka, von Känel, Gander, \& Fischer, 2004; Siegrist \& Li, 2016). Thus, overcommitment is a non-advisable way to deal with work stress, yet overcommitted professionals find it hard to overcome overcommitment.

We examine whether a more controllable motivational process, work goal engagement (Haase, Heckhausen, \& Silbereisen, 2012), mitigates the negative effects of overcommitment on work and health outcomes. Because engaging in work goals implies that individuals are active agents in their own (work) life (Haase et al., 2012; Heckhausen, Wrosch, \& Schulz, 2010, 2019), it should make a difference for overcommitted employees if they dedicate their time and energy to work goals they feel motivationally attached to-or if they dedicate their time and energy to endeavors they do not really feel a motivational attachment to (i.e., unengaged overcommitment). Negative outcomes of overcommitment should be more severe when employees are overcommitted but unengaged, while negative effects should be attenuated when employees are engaged in work goals. We investigate these questions using longitudinal data from 752 employees. As work and health outcomes, we use their job and sleep satisfaction ratings (Buysse, 2014; Kinicki, McKee-Ryan, Schriesheim, \& Carson, 2002).

With our longitudinal design, we are in a position to corroborate prior studies on the negative outcomes of overcommitment (e.g., Kudielka et al., 2004) and then move one important step forward by highlighting the relevance of goal engagement for well-being and adaptive 
development in the work domain. Workers might benefit from motivational processes that alleviate maladaptive ways of dealing with work stress. Thus, practically, this research suggests that employees should reflect on their work-related goals, while employers should communicate meaningful goals and provide opportunities for goal pursuit.

\section{Theoretical Background and Hypothesis Development}

Overcommitment has been conceptualized within the effort-reward imbalance model (ERI; Siegrist, 1996). In this model, the combination of high efforts and low rewards results in work stress with adverse health effects in the long run (Siegrist, 1996). While efforts and rewards are considered extrinsic stress components, overcommitment is regarded as an intrinsic component that involves excessive engagement (Siegrist, 1996; Siegrist \& Li, 2016). It has been theorized as a maladaptive coping pattern that moderates the effect of effort-reward imbalance on health such that the strongest negative effects are expected among highly overcommitted individuals (Siegrist, 1996; Siegrist \& Li, 2016). Further, overcommitment has been expected to show direct effects on individuals' health (Siegrist \& Li, 2016). Research has indeed demonstrated mainly direct effects, for example negative effects on cardiovascular and immune response variables (Siegrist $\& \mathrm{Li}, 2016)$. Further studies have linked overcommitment with job dissatisfaction, exhaustion, and poor sleep quality (e.g., de Jonge et al., 2000; Kudielka et al., 2004). We also examine direct effects and aim to replicate the finding that overcommitment is detrimental to job and sleep satisfaction:

Hypothesis 1: Controlling for the outcomes at Time 1, high overcommitment at Time 1 is associated with (a) low job satisfaction and (b) low sleep satisfaction at Time 3.

Although it is debated whether overcommitment is a state or a trait (du Prel et al., 2018), it has been shown to be relatively stable over time (de Jonge et al., 2008). It is non-responsive to 
changes in freedom of choice at work and increases as work stress increases (du Prel et al., 2018). We therefore investigate if work goal engagement as a more controllable motivational process (Haase et al., 2012) alleviates negative effects of overcommitment.

In contrast to overcommitment, goal engagement—-the process individuals experience once they have committed to a goal—is generally linked to better health and well-being (e.g., Haase, Heckhausen, \& Köller, 2008; Haase et al., 2012; Hall, Chipperfield, Heckhausen, \& Perry, 2010) and is considered a key process of developmental regulation in the major theories of developmental psychology (e.g., Baltes \& Baltes, 1990; Brandtstädter \& Rothermund, 2002; Heckhausen et al., 2010, 2019). Within the motivational theory of life-span development (Heckhausen et al., 2010), three facets of goal engagement are distinguished, selective primary control (i.e., investment of effort, time, and skills), compensatory primary control (i.e., seeking out help or other means to overcome shortcomings in primary control resources), and selective secondary control (i.e., volitional self-regulation to enhance commitment to a chosen goal). Together, these facets operate as goal engagement and have been linked with life satisfaction, purpose in life, and better self-reported physical health (i.e., indicators of adaptive development; Haase et al., 2008; Haase et al., 2012; Haynes, Heckhausen, Chipperfield, Perry, \& Newall, 2009).

Because goal engagement involves individual agency, it might help to maintain a feeling of control over the workplace even for overcommitted employees who are not able to withdraw from their preoccupation with work. That is, we suggest that work goal engagement mitigates the negative effects of overcommitment on work and health outcomes:

Hypothesis 2: Controlling for the outcomes at Time 1, associations between overcommitment at Time 1 and (a) job satisfaction and (b) sleep satisfaction at Time 3 are 
moderated by work goal engagement at Time 2 . When work goal engagement is low, high overcommitment is associated with low job satisfaction and low sleep satisfaction. When work goal engagement is high, such associations do not exist or are considerably weaker.

\section{Method}

\section{Sample}

We used data from the Innovation Sample of the German Socio-Economic Panel (SOEPIS), a longitudinal study established in 2011. Data were collected via face-to-face interviews (see Richter \& Schupp, 2015; further information, including codebooks and questionnaires, is available via www.diw.de/doi/soep.is.2016.2). We used data from 2011 (T1), 2012 (T2), and 2013 (T3), because overcommitment was assessed in 2011, work goal engagement in 2012, and job and sleep satisfaction were assessed in all years. We used the subsample of participants that provided data on our variables of interest and reported to be employed in all three years. Our sample thus consisted of $N=752$ employees ( $48.5 \%$ female, $M=44.97$ years, $S D=11.34$ years, range 18-65 years). Sensitivity analyses (Faul, Erdfelder, Lang, \& Buchner, 2007) yielded an effect size of $f^{2}=.01046$. That is, a small effect can be reliably detected with our given sample of $N=752(\alpha=.05$, power $=.80)$.

Of our sample, 455 (60.5\%) were white-collar workers/employees, $145(19.3 \%)$ were blue-collar workers, $71(9.4 \%)$ were self-employed, 51 (6.8\%) were civil servants, $27(3.6 \%)$ were trainees, and one person $(0.1 \%)$ was helping a self-employed family member. Two individuals $(0.3 \%)$ made no comment about their occupation but provided work goal engagement and overcommitment assessments; thus, we kept them in the sample. Of the sample, 207 (27.5\%) reported managerial responsibilities. 


\section{Measures}

Overcommitment was measured at Time 1, work goal engagement at Time 2, and job and sleep satisfaction data were used from Time 1 and 3. As control variables, we included age and negative affect (T1), because they might affect our criterion variables (Dobrow Riza, Ganzach, \& Liu, 2018; Jacobs, Cohen, Hammerman-Rozenberg, \& Stessman, 2006; Judge \& Ilies, 2004; Kafetsios \& Zampetakis, 2008; Ng \& Feldman, 2010). As to these key constructs, there were no missing data. Internal consistencies are displayed in Table 1.

Overcommitment. The six-item scale from Joksimovic et al. (2002) was used. A sample item was "Work rarely lets me go, it is still on my mind when I go to bed." Participants responded on a scale from 1 (strongly disagree) to 4 (strongly agree).

Work goal engagement. Participants were asked to think of their working life. Then, work goal engagement was measured by six items, two for each facet, on a scale from 0 (strongly disagree) to 10 (strongly agree), for example "When I encounter problems, I don't give up until I solve them” (selective primary control), "If I can't attain a goal one way, I look for alternative ways to still get to it" (compensatory primary control), and "When I have decided on a goal, I always keep in mind its benefits" (selective secondary control; Schöllgen, Gerstorf, \& Heckhausen, 2014). ${ }^{1}$

Job satisfaction and sleep satisfaction. Satisfaction was measured by single items ("How satisfied are you with your job?" and "How satisfied are you with your sleep?"; Richter, Metzing, Weinhardt, \& Schupp, 2013) on a scale from 0 (highly dissatisfied) to 10 (highly satisfied). 
Negative affect. This construct was measured by three items (Schimmack, 2009) on a scale from 1 (very rarely) to 5 (very often). Participants reported how often they felt "angry," "sad," or "worried" in the past four weeks. ${ }^{2}$

\section{Results}

Table 1 displays means, standard deviations, and correlations among the study variables. To test hypotheses, we conducted hierarchical regression analyses predicting job and sleep satisfaction (T3) from overcommitment (T1) and work goal engagement (T2). Table 2 displays the results. We report unstandardized coefficients in the text and standardized ones in the Table.

Hypothesis 1 proposed that higher overcommitment is associated with lower job and sleep satisfaction at Time 3, controlling for both outcomes at Time 1. Supporting Hypothesis 1, higher overcommitment was indeed predictive of both lower job satisfaction $(B=-.170, p=$ $\left..008, f^{2}=.0087\right)$ and lower sleep satisfaction $\left(B=-.138, p=.048, f^{2}=.0054\right)$. Analyses further demonstrated that higher work goal engagement was related to both higher job satisfaction $(B=$ $\left..210, p=.005, f^{2}=.0112\right)$ and higher sleep satisfaction $\left(B=.264, p=.001, f^{2}=.0138\right)$.

In Hypothesis 2, we proposed an interaction effect between overcommitment and work goal engagement in contributing to job and sleep satisfaction. We found that work goal engagement significantly moderated associations between overcommitment at Time 1 and job satisfaction at Time $3\left(B=.192, p=.006, f^{2}=.01013\right)$, but there was no interaction effect for sleep satisfaction $\left(B=.007, p=.93, f^{2}<.001\right)$. As recommended (Cohen \& Cohen, 1983), we plotted the significant interaction (see Figure 1). Simple slope tests revealed that the association between overcommitment (T1) and job satisfaction (T3) was statistically significant for low work goal engagement $(B=-.379, t=-3.99, p<.001)$, but not for high work goal engagement $(B=.005, t=.053, p=.96)$. That is, higher overcommitment was associated with lower job 
satisfaction two years later when work goal engagement was low, but not when it was high. In sum, Hypothesis 2 was supported for the outcome of job satisfaction, but not for sleep satisfaction. $^{3}$

\section{Discussion}

We aimed to replicate research on the effects of overcommitment and to extend research by highlighting the moderating role of work goal engagement in this context. We found that higher overcommitment was associated with lower job and sleep satisfaction two years later, whereas we found the reverse associations for work goal engagement. Moreover, we found that overcommitment only predicted lower job satisfaction when work goal engagement was low. For predicting sleep satisfaction, no interaction effect was evident.

Our study suggests that job satisfaction is more severely affected if employees display unengaged overcommitment. This finding is practically relevant because job satisfaction is linked with many important variables of the work domain, such as job performance, withdrawal behaviors, and organizational commitment (Kinicki et al., 2002). That is, decreases in job satisfaction might have further detrimental consequences. As to sleep satisfaction, it seems that work goal engagement cannot lessen the objective load that is associated with overcommitment; sleeping troubles are probably an inherent part of overcommitment (Joksimovic et al., 2002) that is not alleviated by goal engagement.

\section{Implications}

This analysis has applied a central construct of the motivational theory of life-span development, goal engagement, to the work domain (Heckhausen et al., 2010). Findings highlight the importance of work goal engagement for job satisfaction and thus adaptive development in the work context. Our findings also resonate with related research showing that 
the impact of maladaptive, excessive work mentalities can be attenuated by motivational variables (Ten Brummelhuis, Rothbard, \& Uhrich, 2017). Our study emphasizes the importance of work goals, while Ten Brummelhuis and colleagues (2017) show the importance of work enjoyment. Although interaction effects are often small (Murphy \& Russell, 2017), our findings pertain to the work context and thus millions of people, thereby having ramifications for entire societies both economically and regarding public health in terms of risks for exhaustion. That is, for overcommitted professionals, even small improvements in work satisfaction can be relevant and should be worth the effort. For the effort-reward-imbalance model (Siegrist, 1996), our results are in line with research that has examined overcommitment as a risk factor on its own (de Jonge et al., 2008). However, future research could also include extrinsic work efforts and rewards so as to examine the full ERI-model in this context.

Practically, this research points to beneficial effects of engagement in work goals. Thus, employees should sometimes take one step back and reflect on their priorities and work goals. Likewise, employers should make sure to develop and to explain meaningful organizational goals that employees can identify with (Latham, Erez, \& Locke, 1988); and, importantly, employers should create an environment that provides opportunities and resources for employees' goal pursuit (Heckhausen, Shane, \& Kanfer, 2017; Locke \& Latham, 2002). Besides engaging in work goals, employees should aim to develop adaptive coping styles to counter work stress. Even though overcommitment seems hard to change, overcommitted employees should try to find ways to get their mind off work and to recover (Sonnentag, Kuttler, \& Fritz, 2010).

\section{Limitations and Future Research}

Despite the large sample and the longitudinal design, several limitations need to be acknowledged: Our analyses rely on self-reports from a single source, thus common method bias 
cannot be ruled out (Podsakoff, MacKenzie, Lee, \& Podsakoff, 2003). Yet, our focus was on the interaction between overcommitment and work goal engagement, and interactions cannot be artificially created by common method variance (Siemsen, Roth, \& Oliveira, 2010). ${ }^{4}$ Murphy and Russell (2017) have also pointed out that interaction effects are often small. ${ }^{5}$

Further limitations concern causal conclusions and single item measures. Although we were able to control for Time 1 outcome measures, we cannot draw definite causal inferences. Moreover, we used single items for the assessment of job and sleep satisfaction. Although single items are accepted to proxy job satisfaction, for example (de Jonge et al., 2000; Wanous, Reichers, \& Hudy, 1997), more comprehensive measures would be preferable. Future research should also consider the processes by which goal engagement moderates the effect of overcommitment on job satisfaction. For example, it is possible that behavioral investment in one's work is more effortful when goal engagement is low. That is, when employees display unengaged overcommitment, they lack a sense of direction at work. Continuing investment is only possible with heightened self-regulatory effort and in the long run may lead to increased risks for exhaustion. Further longitudinal research could also take the perspective of goal-setting theory (Locke \& Latham, 2002, 2006) and include variables pertaining to goal choice, performance, and satisfaction with performance.

In conclusion, our analysis suggests that overcommitment affects job satisfaction more severely when employees display low work goal engagement. Thus, this research highlights the importance of goal engagement for adaptive development in the work domain. 


\section{References}

Achtziger, A., \& Gollwitzer, P, (2018). Motivation and volition in the course of action. In: J. Heckhausen \& H. Heckhausen (Eds.), Motivation and action (pp. 485-527). New York, NY: Springer.

Baltes, P. B., \& Baltes, M. M. (1990). Psychological perspectives on successful aging: The model of selective optimization with compensation. In P. B. Baltes \& M. M. Baltes (Eds.), Successful aging: Perspectives from the behavioral sciences (pp. 1-34). New York, NY: Cambridge University Press.

Becker, T. E., Atinc, G., Breaugh, J. A., Carlson, K. D., Edwards, J. R., \& Spector, P. E. (2016). Statistical control in correlational studies: 10 essential recommendations for organizational researchers. Journal of Organizational Behavior, 37, 157-167. doi: 10.1002/job.2053

Brandtstädter, J., \& Rothermund, K. (2002). The life-course dynamics of goal pursuit and goal adjustment: A two-process framework. Developmental Review, 22, 117-150. doi: 10.1006/drev.2001.0539

Buysse, D. J. (2014). Sleep health: Can we define it? Does it matter?. Sleep, 37, 9-17. doi: 10.5665/sleep. 3298

Cohen, J., \& Cohen, P. (1983). Applied multiple regression/correlation analyses for the behavioral sciences (2nd ed.). Hillsdale, NJ: Erlbaum.

De Jonge, J., Bosma, H., Peter, R., \& Siegrist, J. (2000). Job strain, effort-reward imbalance and employee well-being: A large-scale cross-sectional study. Social Science \& Medicine, 50, 1317-1327. doi: 10.1016/S0277-9536(99)00388-3 
De Jonge, J., Van Der Linden, S., Schaufeli, W., Peter, R., \& Siegrist, J. (2008). Factorial invariance and stability of the effort-reward imbalance scales: A longitudinal analysis of two samples with different time lags. International Journal of Behavioral Medicine, 15, 62-72. doi: 10.1007/BF03003075

Dobrow Riza, S., Ganzach, Y., \& Liu, Y. (2018). Time and job satisfaction: A longitudinal study of the differential roles of age and tenure. Journal of Management, 44, 2558-2579. doi: $10.1177 / 0149206315624962$

Du Prel, J. B., Runeson-Broberg, R., Westerholm, P., Alfredsson, L., Fahlén, G., Knutsson, A., Nordin, M., \& Peter, R. (2018). Work overcommitment: Is it a trait or a state?. International Archives of Occupational and Environmental Health, 91, 1-11. doi: $10.1007 / \mathrm{s} 00420-017-1253-8$

Faul, F., Erdfelder, E., Lang, A. G., \& Buchner, A. (2007). G* Power 3: A flexible statistical power analysis program for the social, behavioral, and biomedical sciences. Behavior Research Methods, 39, 175-191. doi: 10.3758/BF03193146

Haase, C. M., Heckhausen, J., \& Köller, O. (2008). Goal engagement during the school-work transition: Beneficial for all, particularly for girls. Journal of Research on Adolescence, 18, 671-698. doi: 10.1111/j.1532-7795.2008.00576.x

Haase, C. M., Heckhausen, J., \& Silbereisen, R. K. (2012). The interplay of occupational motivation and well-being during the transition from university to work. Developmental Psychology, 48, 1739-1751. doi: 10.1037/a0026641

Hall, N. C., Chipperfield, J. G., Heckhausen, J., \& Perry, R. P. (2010). Control striving in older adults with serious health problems: A 9-year longitudinal study of survival, health, and well-being. Psychology and Aging, 25, 432-445. doi: 10.1037/a0019278 
Haynes, T. L., Heckhausen, J., Chipperfield, J. G., Perry, R. P., \& Newall, N. E. (2009). Primary and secondary control strategies: Implications for health and well-being among older adults. Journal of Social and Clinical Psychology, 28, 165-197. doi: $10.1521 /$ jscp.2009.28.2.165

Heckhausen, J., Shane, J., \& Kanfer, R. (2017). Competence and motivation at work throughout adulthood: Making the most of changing capacities and opportunities. In: A. J. Elliot, C. S. Dweck, \& D. S. Yeager (Eds.). Handbook of competence and motivation: Theory and application (2nd ed., pp. 449-470). New York, NY: Guilford Press.

Heckhausen, J., Wrosch, C., \& Schulz, R. (2010). A motivational theory of life-span development. Psychological Review, 117, 32-60. doi: 10.1037/a0017668

Heckhausen, J., Wrosch, C., \& Schulz, R. (2019). Agency and motivation in adulthood and old age. Annual Review of Psychology, 70, 191-217. doi: 10.1146/annurev-psych-010418103043

Jacobs, J. M., Cohen, A., Hammerman-Rozenberg, R., \& Stessman, J. (2006). Global sleep satisfaction of older people: The Jerusalem Cohort Study. Journal of the American Geriatrics Society, 54, 325-329. doi: 10.1111/j.1532-5415.2005.00579.x

Joksimovic, L., Starke, D., Knesebeck, O., \& Siegrist, J. (2002). Perceived work stress, overcommitment, and self-reported musculoskeletal pain: Across-sectional investigation. International Journal of Behavioral Medicine, 9, 122-138. doi: 10.1207/S15327558IJB M0902_04

Judge, T. A., \& Ilies, R. (2004). Affect and job satisfaction: A study of their relationship at work and at home. Journal of Applied Psychology, 89, 661-673. doi: 10.1037/00219010.89.4.661 
Kafetsios, K., \& Zampetakis, L. A. (2008). Emotional intelligence and job satisfaction: Testing the mediatory role of positive and negative affect at work. Personality and Individual Differences, 44, 712-722. doi: 10.1016/j.paid.2007.10.004

Kinicki, A. J., McKee-Ryan, F. M., Schriesheim, C. A., \& Carson, K. P. (2002). Assessing the construct validity of the Job Descriptive Index: A review and meta-analysis. Journal of Applied Psychology, 87, 14-32. doi: 10.1037//0021-9010.87.1.14

Klein, H. J., Wesson, M. J., Hollenbeck, J. R., Wright, P. M., \& DeShon, R. P. (2001). The assessment of goal commitment: A measurement model meta-analysis. Organizational Behavior and Human Decision Processes, 85, 32-55. doi: 10.1006/obhd.2000.2931

Kudielka, B. M., Von Känel, R., Gander, M. L., \& Fischer, J. E. (2004). Effort-reward imbalance, overcommitment and sleep in a working population. Work \& Stress, 18 , 167-178. doi: 10.1080/02678370410001731785

Latham, G. P., Erez, M., \& Locke, E. A. (1988). Resolving scientific disputes by the joint design of crucial experiments by the antagonists: Application to the Erez-Latham dispute regarding participation in goal setting. Journal of Applied Psychology, 73, 753-772. doi: 10.1037/0021-9010.73.4.753

Locke, E. A., \& Latham, G. P. (2002). Building a practically useful theory of goal setting and task motivation: A 35-year odyssey. American Psychologist, 57, 705-717. doi: 0.1037//0003-066X.57.9.705

Locke, E. A., \& Latham, G. P. (2006). New directions in goal-setting theory. Current Directions in Psychological Science, 15, 265-268. doi: 10.1111/j.1467-8721.2006.00449.x 
Murphy, K. R., \& Russell, C. J. (2017). Mend it or end it: Redirecting the search for interactions in the organizational sciences. Organizational Research Methods, 20, 549-573. doi: $10.1177 / 1094428115625322$

Muthén, L. K., \& Muthén, B. O. (2012). Mplus user's guide (7th edition). Los Angeles, CA: Muthén \& Muthén.

Ng, T. W., \& Feldman, D. C. (2010). The relationships of age with job attitudes: A meta-analysis. Personnel Psychology, 63, 677-718. doi: 10.1111/j.1744$6570.2010 .01184 . x$

Podsakoff, P. M., MacKenzie, S. B., Lee, J. Y., \& Podsakoff, N. P. (2003). Common method biases in behavioral research: A critical review of the literature and recommended remedies. Journal of Applied Psychology, 88, 879-903. doi: 10.1037/0021-9010.88.5.879

Richter, D., Metzing, M., Weinhardt, M., \& Schupp, J. (2013). SOEP scales manual (No. 138). SOEP Survey Papers.

Richter, D., \& Schupp, J. (2015). The SOEP Innovation Sample (SOEP IS). Schmollers Jahrbuch, 135, 389-399. doi: 10.3790/schm.135.3.389

Schimmack, U. (2009). Measuring wellbeing in the SOEP. Schmollers Jahrbuch, 129, 241-249.

Schöllgen, I., Gerstorf, D., \& Heckhausen, J. (2014). Control strivings in the Socio-Economic Panel (SOEP). SOEPpaper No. 727. doi: 10.2139/ssrn.2554456

Siegrist, J. (1996). Adverse health effects of high-effort/low-reward conditions. Journal of Occupational Health Psychology, 1, 27-41. doi: 10.1037/1076-8998.1.1.27

Siegrist, J., \& Li, J. (2016). Associations of extrinsic and intrinsic components of work stress with health: A systematic review of evidence on the effort-reward imbalance model. 
International Journal of Environmental Research and Public Health, 13, 432. doi: 10.3390/ijerph13040432

Siemsen, E., Roth, A., \& Oliveira, P. (2010). Common method bias in regression models with linear, quadratic, and interaction effects. Organizational Research Methods, 13, 456-476. doi: $10.1177 / 1094428109351241$

Sonnentag, S., Kuttler, I., \& Fritz, C. (2010). Job stressors, emotional exhaustion, and need for recovery: A multi-source study on the benefits of psychological detachment. Journal of Vocational Behavior, 76, 355-365. doi: 10.1016/j.jvb.2009.06.005

Ten Brummelhuis, L. L., Rothbard, N. P., \& Uhrich, B. (2017). Beyond nine to five: Is working to excess bad for health?. Academy of Management Discoveries, 3, 262-283. doi: 10.5465/amd.2015.0115

Wanous, J. P., Reichers, A. E., \& Hudy, M. J. (1997). Overall job satisfaction: How good are single-item measures? Journal of Applied Psychology, 82, 247-252. doi: 10.1037/00219010.82 .2 .247 


\section{Footnotes}

${ }^{1}$ The motivational theory of life-span development differentiates between motivation and volition (see review in Achtziger \& Gollwitzer, 2019; Heckhausen et al., 2019). Motivation comprises the incentives or reasons why a particular goal is chosen and volition comprises the degree to which and the strategies involved in pursuing a chosen goal. Goal engagement reflects volitional investment. Therefore, extrinsic and intrinsic incentives are not part of the goal engagement scale. Please also note that the measurement of goal engagement is different from the measurement of goal commitment (Locke \& Latham, 2002; Klein, Wesson, Hollenbeck, Wright \& DeShon, 2001). Although both constructs are similar and generally refer to the psychological attachment to a given goal, the measurement of goal engagement includes three facets - selective primary control, selective secondary control, and compensatory primary control — that are not considered in the measurement of goal commitment (Klein et al., 2001).

${ }^{2}$ As to construct validity, confirmatory factor analyses, using the maximum likelihood estimation method in Mplus, demonstrated a good fit for the three-factor solution (overcommitment; work goal engagement; negative affect; $\chi^{2}=197.28, d f=87$, RMSEA $=.04$, $\mathrm{CFI}=.96, \mathrm{TLI}=.95, \mathrm{SRMR}=.04)$ and unsatisfactory fit indices for a two-factor solution (overcommitment and negative affect combined; work goal engagement; $\chi^{2}=488.42, d f=89$, $\mathrm{RMSEA}=.08, \mathrm{CFI}=.85, \mathrm{TLI}=.83, \mathrm{SRMR}=.07)$ or a one-factor solution $\left(\chi^{2}=1654.23, d f=\right.$ $90, \mathrm{RMSEA}=.15, \mathrm{CFI}=.43, \mathrm{TLI}=.34, \mathrm{SRMR}=.15)$. This suggests that our constructs are distinct.

${ }^{3}$ In line with the recommendations of Becker et al. (2016), we also conducted all analyses without control variables. All result patterns remained stable if either one or both control variables, age and negative affect, were excluded. For exploratory purposes, we also ran our 
analyses using gender and years of education as additional control variables; all result patterns were stable. We further ran our analyses in Mplus (i.e., as a latent moderated structural equation model, using the XWITH command; Muthén \& Muthén, 2012). Again, all result patterns remained stable. Because Mplus does not provide traditional fit indices for models with latent variable interactions, we decided to report the hierarchical regression analysis and not the latent moderated model in greater detail in this article.

${ }^{4}$ The study also involves several recommended techniques to control for method biases (Podsakoff et al., 2003): Predictor, moderator, and criterion variables were temporally separated in our longitudinal design; further, our key constructs involved different response formats. Due to the large data collection effort in the context of the SOEP Innovation Sample, our hypotheses were not salient for respondents. Apart from study design, our confirmatory factor analyses (see footnote 2) further indicate that there is no single factor accounting for the majority of the covariance among the measures.

${ }^{5}$ Further, our study complies with the general recommendations of Murphy and Russell (2017) in terms of moderator research: Our $N$ is larger than 500, predictor and moderator are not correlated, their reliabilities are not much below $.80-.85$, and predictor and moderator are not too strongly related to the criterion variables. 
Table 1

Means, Standard Deviations, Reliabilities, and Intercorrelations of Study Variables

\begin{tabular}{|c|c|c|c|c|c|c|c|c|c|c|}
\hline & $M$ & $S D$ & 1 & 2 & 3 & 4 & 5 & 6 & 7 & 8 \\
\hline 1 Overcommitment T1 (1-4) & 2.20 & 0.67 & $(.79)$ & & & & & & & \\
\hline 2 Work goal engagement T2 $(0-10)$ & 7.46 & 1.39 & -.01 & $(.78)$ & & & & & & \\
\hline 3 Negative affect T1 (1-5) & 2.28 & 0.70 & $.18 * *$ & $-.10 * *$ & $(.64)$ & & & & & \\
\hline 4 Age & 44.97 & 11.34 & $.08 *$ & -.02 & .04 & - & & & & \\
\hline 5 Job satisfaction T1 $(0-10)$ & 7.23 & 1.96 & $-.16^{* *}$ & $.15^{* *}$ & $-.29 * *$ & -.01 & - & & & \\
\hline 6 Sleep satisfaction T1 (0-10) & 7.09 & 2.12 & $-.21 * *$ & $.11 * *$ & $-.38 * *$ & -.05 & $.32 * *$ & - & & \\
\hline 7 Job satisfaction T3 (0-10) & 7.10 & 1.90 & $-.17 * *$ & $.16^{* *}$ & $-.24 * *$ & $-.08 *$ & $.40^{* *}$ & $.25^{* *}$ & - & \\
\hline 8 Sleep satisfaction T3 $(0-10)$ & 6.80 & 2.16 & $-.18 * *$ & $.16^{* *}$ & $-.25^{* *}$ & $-.09 *$ & $.20 * *$ & $.50 * *$ & $.35^{* *}$ & - \\
\hline
\end{tabular}

Note. $N=752$. Cronbach's alphas are presented on the diagonal. Variable ranges are displayed in parentheses in the first column.

$* p \leq .05 . * * \leq .01$ 
Table 2

Hierarchical Moderated Regression Analyses Predicting Job and Sleep Satisfaction (T3) from Overcommitment (T1) and Work Goal Engagement (T2)

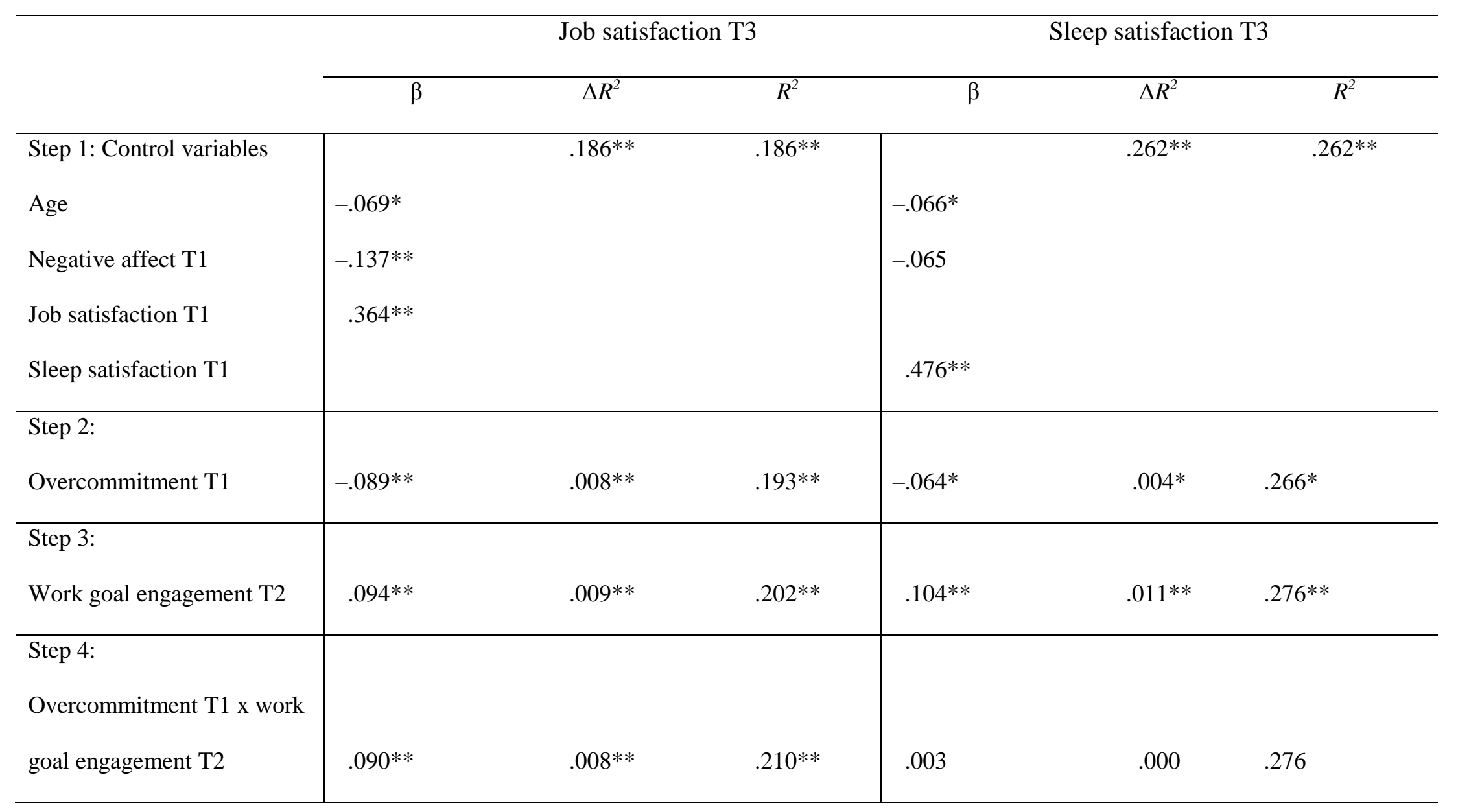

Note. $N=752$. Beta weights are standardized. Predictors and control variables were standardized for analysis. ${ }^{*} p \leq .05 .{ }^{* *} p \leq .01$. 


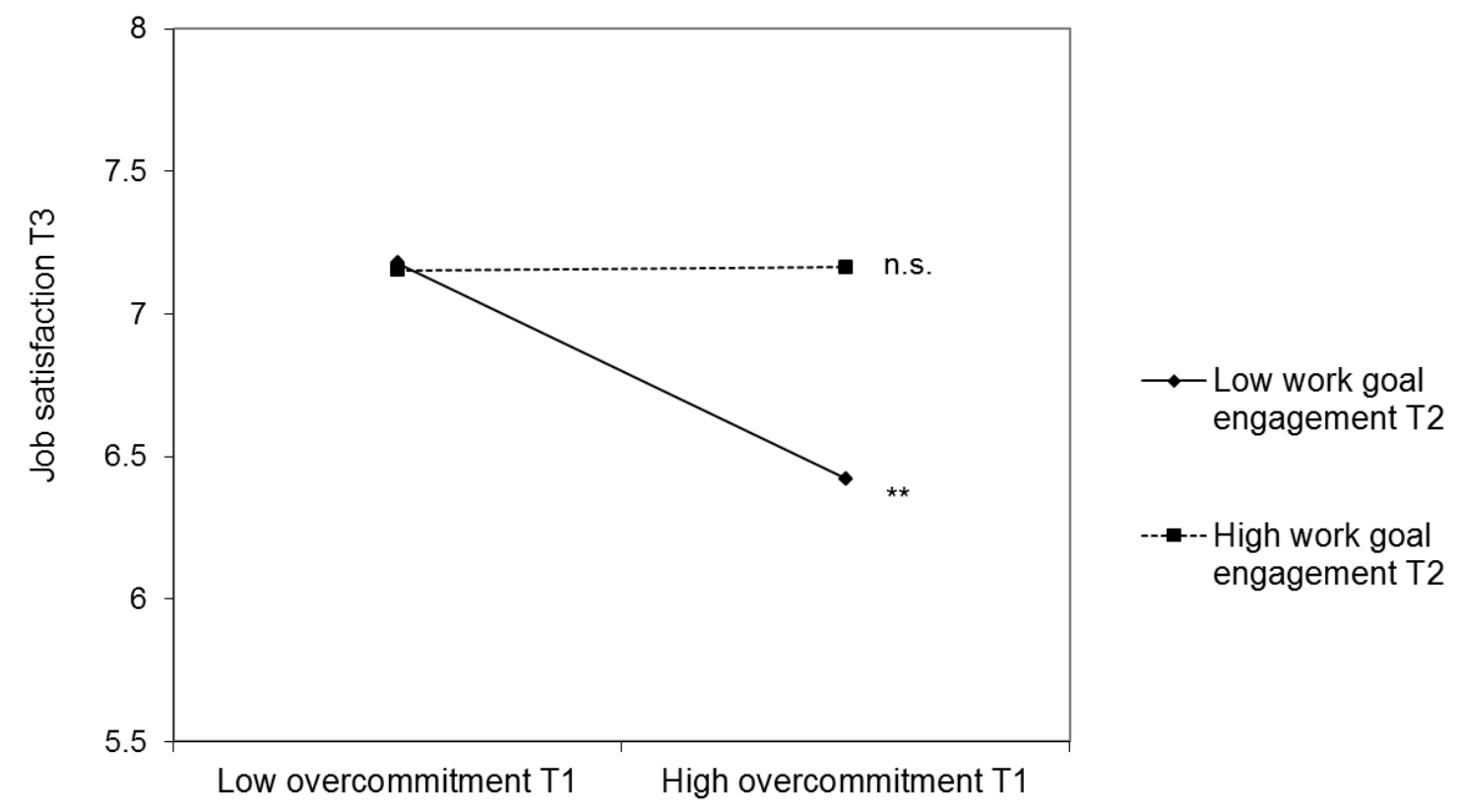

Figure 1. The moderating effect of work goal engagement at Time 2 in the relationship between overcommitment at Time 1 and job satisfaction at Time 3. Higher and lower levels of work goal engagement represent one standard deviation above and below the mean. $* * p \leq .001$. 